\title{
An Optimisation Model for Use of the Vi Polysaccharide Vaccine to Prevent Typhoid in Developing Countries
}

\section{Donald T. Lauria ${ }^{1}$, Brian Maskery ${ }^{1}$, Christine}

Poulos $^{2}$ and Dale Whittington ${ }^{3}$

January 2008

${ }^{1}$ University of North Carolina at Chapel Hill, Chapel Hill, NC, 27599

${ }^{2}$ Research Triangle Institute, Durham, NC, USA

${ }^{3}$ University of North Carolina at Chapel Hill, and the Manchester Business School

\section{BWPI Working Paper 18}

Creating and sharing knowledge to help end poverty 


\section{Abstract}

This article considers the investment case for using the Vi polysaccharide vaccine (Vi) in developing countries from two perspectives: reducing typhoid cases and limiting new health care spending. Consumer demand functions that predict probabilities of adults and children purchasing typhoid vaccinations at different prices are incorporated in a formal mathematical model. This optimisation model solves for the optimal vaccine prices to charge adults and children to maximise the number of typhoid cases avoided subject to the constraint that the sum of 1 ) vaccination revenues, 2) the public savings from avoided cases, and 3) an external (e.g., donor) contribution (if any), is sufficient to pay for the costs of the vaccination program. Using values from the recent literature for South and Southeast Asia for typhoid incidence, Vi vaccine effectiveness, public cost of illness, and vaccination program cost, three mass vaccination policy alternatives are evaluated: charging adults and children different (optimal) prices, charging uniform prices, and providing free vaccines. Assuming differential pricing is politically feasible, the vaccine price for children should be zero (because their incidence is much higher than adults), and fees for adults should cover most of costs of the vaccination program (because the savings from reduced public sector treatment are small). Equal prices for children and adults produce very similar results to the optimal solution. Alternatively, if vaccines are free, the number of cases is not significantly reduced compared to either pricing policy, but a large external financial contribution would be required.

Keywords: Typhoid vaccine, policy, optimisation, user charges, vaccine demand

Donald Lauria is Professor of Environmental Sciences \& Engineering, University of North Carolina at Chapel Hill, USA

Brian Maskery is PhD Student, Department of Environmental Sciences \& Engineering, School of Public Health, University of North Carolina at Chapel Hill, USA

Christine Poulos is Senior Economist, Research Triangle Institute, Research Triangle Park, North Carolina. USA

Dale Whittington is Professor of Environmental Sciences \& Engineering, and City and Regional Planning, University of North Carolina at Chapel Hill, USA, and Professor, Manchester Business School, UK. 


\section{Introduction}

Typhoid is endemic in many developing countries and remains a substantial public health problem despite recent progress in water and sanitation coverage. The newgeneration Vi polysaccharide vaccine has been shown to be a safe and effective public health intervention against typhoid; Yang et al. (2001) and Acosta et al. (2004) report an efficacy of $60-70 \%$ for $2-3$ years. The $\mathrm{Vi}$ polysaccharide vaccine (Vi) is no longer afforded patent protection and is now manufactured in Vietnam; there are also plans to produce Vi locally in India and Indonesia (DeRoeck et al., 2005). Local production will have the effect of lowering prices; governments must decide whether to use the $\mathrm{Vi}$ polysaccharide vaccine and, if so, how that should be done.

Besides the Vi polysaccharide vaccine for typhoid fever, several governments are considering proposals for the use of other new vaccines for serious diseases such as Japanese encephalitis and cholera. These new vaccines are outside the standard packages of vaccines recommended by the World Health Organisation's Expanded Program on Immunisation (EPI). International vaccine donors such the Global Alliance for Vaccines and Immunisation now want national governments to share the costs of vaccine purchases. Because governments' financial resources for new vaccination programs are limited, they face some hard choices.

The investment case for expanded use of the Vi polysaccharide vaccine in developing countries requires a careful examination of the costs and benefits of different program options. Although we are not aware of any published estimates of the cost of producing $\mathrm{Vi}$ vaccines, considerable information on the costs of delivering vaccines is available from numerous studies over more than a decade. The production plus delivery costs of vaccination programs that use locally produced vaccines are uncertain. Moreover, there is no consensus as to how best to measure the economic benefits of Vi polysaccharide vaccination programs. From the perspective of public health professionals, the main benefits of vaccination are clearly the reduced morbidity and mortality associated with fewer typhoid cases. Assigning a monetary value to this reduction in morbidity and mortality, for comparison with the monetary value of the costs incurred, is either a challenging task or an unnecessary secondary effort, depending on one's point of view.

National health ministries with fixed budgets view new vaccination initiatives somewhat differently because they may have difficulty persuading finance ministers that a larger health budget is required. Health policymakers thus especially want information on how much money any proposed new vaccination program will save the public sector in terms of reduced costs due to treating fewer active cases in government-subsidised hospitals and health clinics. If the discounted cost savings to the health ministry from treating fewer typhoid patients were projected to exceed the cost of a proposed vaccination program, the decision to invest in the new vaccination initiative would be easy if the ministry can access financial markets to pay for the initial costs of the program. But if such cost savings were expected to be less than the costs of the vaccination program, the value of the health outcomes relative to anticipated costs would require a more careful reckoning.

In this article we consider the investment case for wider use of Vi polysaccharide vaccine in developing countries from both of these perspectives simultaneously: the public health objective of reducing the number of typhoid cases, and the financial objective that a new vaccination program not require substantial new government spending. When donor funding is limited, the only way the financial objective can be 
met is to charge users (individual recipients of the inoculation) for the vaccine and, in effect, to use the resulting revenues to offset part of the costs of the vaccination program. But charging user fees for the vaccine conflicts with the public health objective of reducing typhoid cases: some people will be unwilling or unable to pay, leaving themselves vulnerable to typhoid infection. Our primary goal here is to demonstrate a way to use existing data to quantify the tradeoff between reducing typhoid incidence and meeting financial obligations.

We begin with a brief review of previous attempts to use mathematical optimisation models to examine vaccine policy issues. We then present a new optimisation model that incorporates vaccine user charges as a way to overcome financial obstacles to expanded use of new vaccines. Then, we illustrate our model with data that we believe are representative of many typhoid-endemic areas of South and Southeast Asia. Our findings from this exercise touch in various ways on the model's applicability in developing countries, on optimising user charges for vaccines, on cost recovery, and on the implications for funding vaccination programs with limited or no financial assistance from international donors.

\section{Background}

The literature on vaccine policy primarily focuses on the cost effectiveness or cost utility of different vaccines (e.g. Beutels et al., 2007; Lee et al., 2007; Szucs, 2005). The question of how user charges should be determined to balance competing public health and government financial objectives is not typically broached in economic appraisals of vaccination programs.

A number of authors have examined the optimal tax-subsidy scheme for providing vaccines in the presence of herd immunity or herd protection effects (Boulier, Datta and Goldfarb, 2007; Brito, Sheshinski, and Intriligator, 1991; Francis, 1997, 2004). These models typically assume (1) a homogenous population with regard to risk of infection and willingness to pay for risk reduction (though the cost of procuring vaccines may vary in the population) and (2) prospective purchasers understand the relationship between coverage levels and herd protection and behave strategically. At the market equilibrium, the number of vaccines provided is not socially optimal because private decision makers only consider their self-interest when deciding how many vaccines to purchase for their household members. These models solve for the optimal price that equates the marginal social benefit of a vaccine with the marginal cost per fully vaccinated individual.

Kremer and Glennerster (2004) show how governments can provide suitable compensation to multinational vaccine manufactures to engage in vaccine research and development while also achieving static efficiency in vaccine pricing. They propose that governments buy large blocks of vaccines directly from developers at prices that cover production costs plus a reasonable return to research investments. Then, they suggest that governments sell the vaccine to consumers at a price equal to the marginal cost of production, and use tax revenues to offset the difference in purchase price and selling price (i.e. to offset the cost of a reasonable return to research and development). The general question of how to price vaccines in the presence of market power is important, but in our case the $\mathrm{Vi}$ vaccine is no longer patent-protected and local protection is already underway. The issue is thus not relevant for the typhoid vaccine investment case. 
Several studies have been published that use mathematical optimisation techniques for analysing vaccination policies without including user charges as decision variables. For example, Becker and Starczak (1997) describe the use of linear programming to determine the minimum number of vaccinations required to prevent disease epidemics based on strategic allocations among households. They address two separate optimisation problems: 1) the minimum number of vaccinations required to prevent epidemic spread of disease, and 2) the minimum possible average reproduction number given a limitation on available vaccines. They conclude that the optimal allocation of vaccines among households should aim at leaving the same number of susceptible people in every household, which is a function of household size and the effectiveness of the vaccine. Larger households thus require more vaccinations, assuming that susceptibility and infectiousness among individuals are homogenous and that the transmission rate is much greater within households than between them.

Patel et al. (2005) report a model to optimally allocate a limited number of flu vaccines in communities whose populations have been subdivided by age, each with a known influenza "attack rate" (analogous to incidence). Associated with each group is a different assumed weight for the severity of the consequences of a person in that group getting sick; the objective is to find the fraction of persons in each group that should be vaccinated so as to minimise the total "loss" due to illness. Embedded in the optimisation model is a stochastic epidemiological model developed by the authors that describes the propagation of influenza through the community. Model solution is by heuristic programming ("genetic algorithm") which starts with an arbitrary allocation of the vaccines among age groups, followed by estimation of the resulting disease burden based on solving the epidemiological model. The model is iterated through disease burden estimates and vaccine reallocations until convergence is achieved. No consideration is given to costs, economic benefits, or prices. This model produces results similar to those presented by Longini et al. (1978).

Weniger et al. (1998) and Jacobsen et al. (1999) used integer programming to determine the optimal bundling of required (EPI) vaccinations. Their objective is to minimise the total cost of immunisation, including vaccine material costs, clinic costs, and nurses' time, subject to the constraints that 1) a child will receive all of the recommended EPI vaccines and 2) that there are a limited number of opportunities to vaccinate a child (shortly after birth, and at 2, 4, 6, 12-18, and 60 months). These authors also discuss how to minimise the total cost of a vaccination program by combining vaccines into single injections or by giving multiple injections during the same visit, and by improving vaccine storability. The authors do not specify how the government and parents will pay for the vaccinations.

Recently a number of studies have appeared that report on the magnitude of private demand for various vaccines. These include applications of the contingent valuation method (CVM) for estimating private (household) demand for vaccines against diseases such as malaria (Whittington et al., 2003; Cropper et al., 2004), chicken pox (Hsu et al., 2003), HIVIAIDS (Whittington et al., 2002; Suraratdecha et al., 2005), typhoid (Canh et al., 2006), and cholera (Cook et al., 2006; Lucas et al., 2007). But these authors have not used this information on private demand to determine appropriate user charges for vaccines. Nor has this kind of information on private demand been incorporated into either the objective function or the constraint sets of vaccine policy optimisation models. 
The model presented here directly addresses the question of pricing in a usersupported, publicly inaugurated mass vaccination program in an area where public (government and donor) financial support is limited.

\section{Model Formulation}

Let us assume that the government's vaccination policy objective is to maximise the number of typhoid cases avoided, subject to the constraint that the program must be funded through (1) user fees, (2) a fixed contribution from the government or external donor (which could be zero), and (3) the savings realised by avoided (diminishing) public costs of treating active cases, whose number would be reduced by the immunisation program. We may then frame our research question as follows: what vaccine user fees for adults and for children would maximise the number of typhoid cases avoided while still ensuring that the program does not impose excessive financial obligations on the government? The decision (choice) variables in our optimisation model are thus the vaccination prices that should be charged to adults $\left(p_{a}\right)$ and children $\left(p_{c}\right)$ in the target population.

The incidence of typhoid is typically much higher in children than in adults, which has prompted proposals for school-based typhoid vaccination programs that only target children; Pakistan, Vietnam, and Indonesia are all now contemplating the initiation of school-based Vi vaccination (DeRoeck et al., 2005). School-based vaccination programs are an important option for consideration. However, since it is not clear than the cost per vaccinated individual is very different in school-based and mass vaccination programs, in this paper we focus on a mass vaccination program that is open to both children and adults. We can thus examine the possibility of pricing vaccines for adults and children differently; this allows us to consider the option of adults cross-subsidising vaccines for children. In our optimisation model school-based vaccination programs could be evaluated by restricting the provision of vaccines only to school-aged children, but restricting the set of feasible alternatives in advance will typically (but not necessarily) result in an inferior model solution.

In the optimisation model the number of cases of typhoid that will be avoided by instituting a vaccination program is the number of cases that would arise without such a program less the number of cases that would arise with a program. A mass vaccination program will not be able to reach the entire population of a community (e.g., some families may not learn about the vaccination program, may be travelling away from home, or be physically unable to travel to a vaccine outpost). The group of child candidates for vaccination, $N_{c}$, is the product $\theta_{c}{ }^{*} P o p_{c}$ where $P_{o} p_{c}$ is the total child population and $\theta_{c}$ is the fraction of children that can participate in a vaccination program. Correspondingly, $\left(1-\theta_{c}\right)$ is the fraction of children that cannot participate in the vaccination program for whatever reason. The adjustment using $\theta_{c}$ should not be confused with the portion of the population that could participate in the program but chooses not to do so (e.g., because of user fees, skepticism about vaccine efficacy, or a perception that they are not at risk of infection). The adult candidate population can be specified in the same manner.

Let Eff be the percentage reduction (as a fraction) in the expected incidence after vaccination. Assume that if the Vi polysaccharide vaccine is effective, protection starts immediately after vaccination and lasts for 3 years. Also assume that protection remains unchanged each year and is identical for children and adults. (In fact, there is some evidence that efficacy declines somewhat in the third year; this effect could be 
approximated in our model by reducing slightly average efficacy over the duration of protection.) No one in the target population has been vaccinated prior to inception of the new vaccination program: thus everyone is initially at risk of typhoid infection. The annual number of child cases of typhoid in the absence of a yearly vaccination program may be stated as $I_{c} \cdot P_{0} p_{c}$, where $I_{c}=$ childhood incidence of typhoid (cases per year per child). The number of adult cases may be similarly designated using a subscript $a$. The total number of child and adult cases that occur without a program in a 3-year period is then ...

$$
3 \cdot I_{c} \cdot P_{o p_{c}}+3 \cdot I_{a} \cdot P_{o p_{a}}
$$

The number of cases that occur with a vaccination program can be divided between adults and children, then further divided between those who get sick because they were not vaccinated and those who get sick despite being vaccinated (because the vaccine is ineffective for them).

The number of children who are not vaccinated is the sum of those who choose not to purchase the vaccine at the price $p_{c}$ and those who are unable to participate, $\left[1-P_{c}\left(p_{c}\right)\right]$ - $N_{c}+\left[1-\theta_{c}\right] \cdot P_{o} p_{c}$ where $P_{c}\left(p_{c}\right)=$ the probability that a child will be vaccinated if the user fee is $p_{c}$ per vaccination, and $N_{c}=$ the number of candidate children. (The mathematical form of $P_{c}\left(p_{c}\right)$, the coverage-price function for children, is discussed in the next section.) The risk that these children will contract typhoid is obtained by multiplying by the incidence $I_{c}$. If vaccination is offered only once every 3 years, then $I_{c} \cdot\left(\left[1-P_{c}\right.\right.$ $\left.\left.\left(p_{c}\right)\right] \cdot N_{c}+\left[1-\theta_{c}\right] \cdot P o p_{c}\right)=$ the number of unvaccinated children who get sick each year. Thus, in the 3-year period of our analysis, the total number of children and adults who contract typhoid fever because they are not vaccinated is ...

$$
3 \cdot I_{c} \cdot\left(\left[1-P_{c}\left(p_{c}\right)\right] \cdot N_{c}+\left[1-\theta_{c}\right] \cdot P_{o p_{c}}\right)+3 \cdot I_{a} \cdot\left(\left[1-P_{a}\left(p_{a}\right)\right] \cdot N_{a}+\left[1-\theta_{a}\right] \cdot P_{o} p_{a}\right)
$$

The number of children who are vaccinated is $P_{c}\left(p_{c}\right) \cdot N_{c}$, but some of them remain at risk because the vaccine is ineffective: [1 - Eff] $\cdot P_{c}\left(p_{c}\right) \cdot N_{c}$. The expected number of annual child typhoid cases results from multiplying by the incidence $I_{c}$. Hence the total number of child and adult typhoid cases in a 3-year period among persons who have been vaccinated is ...

$$
3 \cdot I_{c} \cdot[1-E f f] \cdot P_{c}\left(p_{c}\right) \cdot N_{c}+3 \cdot I_{a} \cdot[1-E f f] \cdot P_{a}\left(p_{a}\right) \cdot N_{a}
$$

The objective function of the model is to maximise the total number of cases avoided in three years, which is the number of cases in the absence of a vaccination program (equation 1) minus the sum of equations 2 and 3 , which denotes the number of cases with a program; the result is in equation $4 \ldots$

$$
\text { Maximise } Z=3 \cdot E f f \cdot P_{c}\left(p_{c}\right) \cdot N_{c} \cdot I_{c}+3 \cdot E f f \cdot P_{a}\left(p_{a}\right) \cdot N_{a} \cdot I_{a} \text {. }
$$

In the following interpretation of equation 4 , we focus only on the terms that pertain to children as the interpretation for adults is similar.

Consider $P_{c}\left(p_{c}\right) \cdot N_{c}$, the number of children who are vaccinated. Multiplying by vaccine effectiveness yields the number of people actually protected by the vaccine: Eff $\cdot P_{c}\left(p_{c}\right)$ - $N_{c}$. Had they not been vaccinated, they would have been at risk every year. Multiplying by the incidence $I_{c}$ yields the number who would have become infected each year had they not been vaccinated. Note that this objective is equivalent to maximising the weighted sum of child and adult vaccinations, where the weights are the respective incidences of typhoid in children and adults. 
The constraint for this model requires that the sum of (1) revenue from vaccinations, (2) a fixed contribution from the government or external donor, and (3) the equivalent present value of the savings on the public cost of illness avoided during the next three years by having a vaccination program must equal the cost of the program. We consider the fixed contribution, $S$, to be an exogenous variable that would be specified prior to model solution. Revenue from selling vaccines is the product of the number of persons vaccinated and the user fees they pay. This equation is nonlinear in the decision variables $p_{c}$ and $p_{a}$, even if the willingness-to-pay (WTP) functions $P_{c}\left(p_{c}\right)$ and $P_{a}\left(p_{a}\right)$ are linear ...

$N_{c} \cdot P_{c}\left(p_{c}\right) \cdot p_{c}+N_{a} \cdot P_{a}\left(p_{a}\right) \cdot p_{a}$

The annual public sector cost of illness avoided (PSCOIA, in USD per year) is the number of cases avoided each year that the vaccine is effective (i.e. in years 1,2 , and 3 , which is equation 4 divided by 3 ) multiplied by the per unit public cost of treating a typhoid patient ( $\mathrm{COI}_{\mathrm{C}}$ for children, $\mathrm{COI}_{a}$ for adults). PSCOIA needs to be discounted from the end of years 1,2 and 3 to the beginning of year 1 when the vaccination program is launched. This is done by multiplying PSCOIA by the present worth factor (PWF) for an equal annual series, whose formula is PWF $=\left[1-(1+r)^{-3}\right] / r$, where $r=$ the annual rate as a decimal for discounting financial transactions (Barish et al., 1978). We assume a real discount rate of $8 \%$, which corresponds to $\mathrm{PWF}=2.58$. Thus, the equivalent present value of the savings from not having to treat the typhoid cases avoided is shown in equation $6 \ldots$

$$
\mathrm{PWF} \cdot \mathrm{Eff} \cdot\left[I_{c} \cdot P_{c}\left(p_{c}\right) \cdot N_{c} \cdot C O I_{c}+I_{a} \cdot P_{a}\left(p_{a}\right) \cdot N_{a} \cdot C O I_{a}\right]
$$

The cost of the vaccination program is the sum of fixed and variable costs. The fixed cost, $F$, includes such expenses as setting up the cold chain arrangements, the number of outposts, and the social marketing/vaccine publicity campaign. The variable costs include the material cost per dose plus the delivery labor and administrative costs per dose. The variable cost is the product of the number of persons vaccinated and the unit material plus the delivery cost per fully vaccinated individual $\left(C_{c}\right.$ for children, $C_{a}$ for adults):

$$
F+N_{c} \cdot P_{c}\left(p_{c}\right) \cdot C_{c}+N a \cdot P_{a}\left(p_{a}\right) \cdot C_{a}
$$

The revenue neutrality constraint is the sum of the fixed contribution, $S$, equations 5 and 6 less equation 7, with the result set equal to zero:

$$
\begin{aligned}
S+N_{c} \cdot & P_{c}\left(p_{c}\right) \cdot\left[p_{c}+\mathrm{PWF} \cdot E f f \cdot I_{c} \cdot C O I_{c}-C_{c}\right]+ \\
& N_{a} \cdot P_{a}\left(p_{a}\right) \cdot\left[p_{a}+\mathrm{PWF} \cdot E f f \cdot I_{a} \cdot C O I_{a}-C_{a}\right]-F=0 .
\end{aligned}
$$

A health ministry may be unable to capture future $\mathrm{COI}$ savings to finance the initial costs of a vaccination program, in which case equation 6 would be omitted from the revenue neutrality constraint. The policy problem is to find the optimal vaccination user fees (prices) to be charged for adults and children, $p_{a}{ }^{*}$ and $p_{c}{ }^{*}$ (asterisks denote optimal prices), that maximise the number of typhoid cases avoided (equation 4) subject to the revenue neutrality constraint (equation 8 ). 
This derivation ignores the possibility of indirect herd protection effects from the typhoid vaccination program. The initiation of a vaccination program would reduce the number of susceptible and infected persons in the vaccinated subgroup, which may in turn reduce typhoid exposure for the unvaccinated (Haber 1999). However, we are unaware of any empirical evidence of herd immunity from typhoid vaccination programs that could be incorporated into our optimisation model.

The optimality conditions for this model can be derived using Lagrangian analysis. The Lagrangian expression $L$ is equation 4 less the Lagrangian multiplier (a new decision variable, $\lambda$ ) multiplied by the left side of equation 8 . The optimality conditions for user fees are obtained by simultaneously solving the partial derivatives of $L$ and setting them equal to zero. Let us denote $\partial L / \partial p_{a}$ as $L_{a}, \partial L / \partial p_{c}$ as $L_{c}$, and $\partial L / \partial \lambda$ as $L_{\lambda}$.

Before writing the optimality conditions, we need to make an assumption regarding the mathematical form for the WTP functions. For ease of presentation, the WTP functions for both child and adult vaccinations are assumed to be exponential; for example, the equation for children is ...

$$
P_{c}\left(p_{c}\right)=\alpha_{c} \cdot \exp \left(-\beta_{c} \cdot p_{c}\right)
$$

where $P_{c}\left(p_{c}\right)=$ the probability of a child being vaccinated, $\alpha_{c}=$ probability of vaccination if the fee $p_{c}$ is zero, and $\beta_{c}=$ slope of the function. The WTP function for adults is similar to equation 9 except the subscripts for children $(c)$ are replaced by subscripts for adults (a). The derivative of $P_{c}$ with respect to the user fee for children $p_{c}$ is $P_{c}\left(p_{c}\right) \cdot\left(-\beta_{c}\right)$; it is similar for adults $P_{a}\left(p_{a}\right) \cdot\left(-\beta_{a}\right)$. From solving $L_{a}=L_{c}=0$ and setting the two resulting equations equal to each other, we obtain the following expression for optimal child and adult vaccination fees:

$$
\begin{aligned}
& I_{c /}\left[-1 / \beta_{c}+p c^{*}+\mathrm{PWF} \cdot \text { Eff } \cdot I_{c} \cdot C O I_{c}-C_{c}\right]= \\
& I_{a} /\left[-1 / \beta_{a}+p_{a}{ }^{*}+\mathrm{PWF} \cdot \text { Eff } \cdot I_{a} \cdot C O I_{a}-C_{a}\right]
\end{aligned}
$$

and from $L_{\lambda}=0$ we obtain equation 8 . Equations 8 and 10 are the two optimality conditions, which can be solved simultaneously for determining optimal user fees $p_{a}{ }^{*}$ and $p_{c}{ }^{*}$. These two equations indicate all the parameters that affect optimal user fees. Although equation 10 does not include $\alpha_{a}, \alpha_{c}, N_{a}, N_{c}, S$, or $F_{c}$, these parameters do appear in equation 8. In fact, all of the parameters used to develop the model affect optimal user fees. We examine these optimality conditions in the Results section below, but first we discuss the data used for the application of our model to typical conditions in South and Southeast Asia.

\section{Data}

We assume that our target area has a population of one million, of whom 300,000 are children and 700,000 are adults. Annual incidence and public cost of illness (COI) data are available for a number of sites in Asian countries including Hue, Vietnam, Karachi, Pakistan, Kolkata and Delhi, India, Jakarta, Indonesia, and Hechi, China (Bahl et al., 2004; Ochiai et al., 2005; 2006; Poulos et al., 2007). The range of observed incidence varies from 0.2 to 2.5 cases per 1000 adults per year, and from 0.5 to 10 cases per 1000 children per year. The large variance in incidence rates reflects regional differences as well as differences in the samples under surveillance. For example, the surveillance studies undertaken in Kolkata and Delhi included only slums with high incidences, while the study in Hue included the entire city. In this paper, annual incidence of typhoid fever 
in children is assumed to be 3.5 cases per 1,000 children, and annual incidence in adults is assumed to be 1.0 case per 1,000 adults, both of which are within the ranges cited above. Multiplying populations by incidences, the number of new child cases of typhoid each year in our target area in the absence of a vaccination program is 1,050 , and the number of new adult cases is 700 , for a total of 1,750 new cases per year or 5,250 for the 3 -year model planning period, if the child and adult populations and incidences remain constant.

All costs in the examples of this paper are current 2007 values. They are based on several cost studies conducted under the aegis of the International Vaccine Institute (IVI) in South and Southeast Asia (Thiem et al., 2003; Stewart, 2005; Cavalier et al., 2006). The assumed costs for our examples are approximate mean values, but the data upon which they are based are sparse and show substantial variation. The average variable cost of vaccinating an individual (child or adult) in the target area with the $\mathrm{Vi}$ polysaccharide vaccine is estimated to be US\$1.0 via a mass vaccination program that is offered through neighborhood-level medical clinics (MCs). These costs are similar to the actual costs for vaccination trials conducted by the IVI in Hue, Vietnam, in 2003 (Stewart, 2005). The fixed costs for this example are estimated at US $\$ 100,000$, which is a little less than $10 \%$ of total campaign cost if the entire target population was vaccinated. In a recent cholera mass vaccination campaign, the fixed costs for an awareness campaign and vaccine storage facilities composed about $12 \%$ of the total trial costs (Cavalier et al., 2006).

Public COI estimates includes expenditures on physician time, laboratory tests, medicines, overnight treatment stays, and other public treatment expenses. Bahl et al. (2004) estimated that the costs incurred by the Indian public health sector for treating patients with typhoid fever in Delhi was about US\$100 (after adjusting for inflation). In order to compare treatment costs relative to the cost of living, purchasing power parity $(P P P)^{1}$ can be used. For Delhi, the US $\$ 100$ per case estimate corresponds to about PPP $\$ 450$. Additional estimates of public COI are reported by Poulos et al. (2007). These estimates vary by site and the level of public health care provided. In Hechi, China, patients pay the full cost of treatment at public clinics, but in Karachi, Kokata and Jakarta, public clinics provide subsidised treatment. The average public COI per case varies from zero in Hechi to US\$33 (PPP\$140) in Kolkata. Across all six sites, the mean public COI per case is US\$30; this mean value is used for the examples in this paper. We assume COI per case is the same for children and adults. Children's public COI per case was greater than that for adults in Delhi and Jakarta and less than that for adults in Kolkata. It follows that the annual public expenditure for treating typhoid in our target area would be US $\$ 52,500$ if all 1,750 cases per year were treated.

Table 1. Model Parameter Values

\begin{tabular}{lcc}
\hline \multicolumn{1}{c}{ Parameter } & Symbol & Value \\
\hline External contribution & $S$ & 0 \\
& & 0.8 \\
Intercept child demand function $^{\mathrm{a}}$ & $\alpha_{c}$ & 0.1 \\
Slope child demand function $^{\mathrm{a}}$ & $\beta_{c}$ & 0.5 \\
Intercept adult demand function $^{\mathrm{a}}$ & $\alpha_{a}$ & \\
\hline
\end{tabular}

1 The conversion rates are taken from From IMF's April 2007 World Economic Outlook http://www.imf.org/external/pubs/ft/weo/2007 (accessed June 2007) 


\begin{tabular}{|c|c|c|}
\hline Slope adult demand function ${ }^{a}$ & $\beta_{a}$ & 0.2 \\
\hline Total number of children in target area & $N_{c}$ & 300,000 \\
\hline Total number of adults in target area & $N_{a}$ & 700,000 \\
\hline $\begin{array}{l}\text { Child typhoid incidence, cases/year per 1,000 } \\
\text { children }{ }^{\text {b }}\end{array}$ & $I_{c}$ & 3.50 \\
\hline $\begin{array}{l}\text { Adult typhoid incidence, cases/year per 1,000 } \\
\text { adults }{ }^{\text {b }}\end{array}$ & $I_{a}$ & 1.0 \\
\hline New child typhoid cases/ year & $I_{c} \cdot N_{c}$ & 1,050 \\
\hline New adult typhoid cases/ year & $l_{a} \cdot N_{a}$ & 700 \\
\hline $\begin{array}{l}\text { Unit cost of treating illness (COI) children \& } \\
\text { adults (US\$) }\end{array}$ & $\mathrm{COI}_{c}$ and $\mathrm{COI}_{a}$ & 30 \\
\hline $\begin{array}{l}\text { Expenditure on COI if all cases treated } \\
\text { (US\$/year) }\end{array}$ & $\begin{aligned} \mathrm{COI}_{c} \cdot \mathrm{I}_{c} & \cdot \mathrm{N}_{c}+\mathrm{COI}_{a} \cdot \mathrm{I}_{a} \\
& \cdot N_{a}\end{aligned}$ & 43,750 \\
\hline Unit cost of vaccination at medical centers (US\$) & $C_{c}$ and $C_{a}$ & 1.0 \\
\hline $\begin{array}{l}\text { Fixed cost of vaccination program at medical } \\
\text { centers (US\$) }\end{array}$ & $F$ & 100,000 \\
\hline$V^{2}$ accine efficacy ${ }^{\mathrm{C}}$ & Eff & 0.70 \\
\hline
\end{tabular}

a Data estimated from Canh et al., 2006; Cook et al., 2006.

${ }^{b}$ Data taken from Poulos et al., 2007

${ }^{\mathrm{c}}$ From Acosta et al., 2004.

Two studies on private demand for the Vi polysaccharide typhoid vaccine--conducted in Hue, Vietnam and Kolkata, India, for the International Vaccine Institute--constitute the basis for the WTP functions used in this paper (e.g. Canh et al., 2006, Cook et al., 2006). WTP studies that use the contingent valuation method typically ask respondents to indicate the number of vaccines they would purchase for themselves and their family members at proffered prices. Poisson or negative binomial models are fitted to responses, where the dependent variable is the probability that the jth household will purchase $n_{j}$ vaccines; price and household characteristics are treated as explanatory variables on the right hand side. The demand relationships for adult and child vaccines are modeled separately. For example, the probability of purchasing $n_{j}$ child (or adult) vaccines is defined by

$$
P\left[V_{j}^{*}=n_{j}\right]=\frac{e^{\lambda_{j}} \lambda_{j}^{n}}{n_{j} !} \text { for } n_{j}=0,1,2, \ldots,
$$

where $\lambda_{j}=e^{X_{j} \delta}, \delta$ is the vector of regression coefficients, and $X_{j}$ is the vector of characteristics for the $j$ th household in the target area. The mean values $\lambda_{j}$ indicate the expected number of child (or adult) vaccines that will be purchased by the $j$ th household in the target area at the proffered price. Summing over all $j$ households yields the total expected number of child (or adult) vaccines that will be purchased, and dividing by the total number of children (or adults) in the sample yields the fraction of children (or adults) that will be vaccinated at the given price. The exponential WTP functions assumed above in equation 9 can be estimated by fitting them to these fractions using ordinary least squares.

The WTP functions for child and adult vaccinations each have two parameters, $\alpha$ and $\beta$, which are shown in Table 1, along with other data assumed for the target populations. The estimated demand in Hue was higher than in Kolkata for both adults and children. The demand equations used in our optimisation model fall between the estimates for the two sites. Figure 1 shows the graphs of these WTP functions. If child vaccinations are 
free, $80 \%$ of the children will be vaccinated because $\alpha_{c}=0.8$. However, if vaccinations are free for adults, only $50 \%$ will be vaccinated $\left(\alpha_{a}=0.50\right)$. The low adult intercept likely results from lower incidence rates among adults and because respondents believe that the disease is more "serious" for children than for adults. With exponential demand functions, revenues from vaccinations increase as price increases, up to a maximum when the price is $1 / \beta$; for higher prices than this, revenues decrease. Hence the revenue-maximising user fee for children is US\$10 per dose, and for adults it is US\$5.

Figure 1. Willingness to Pay (WTP) Demand Functions

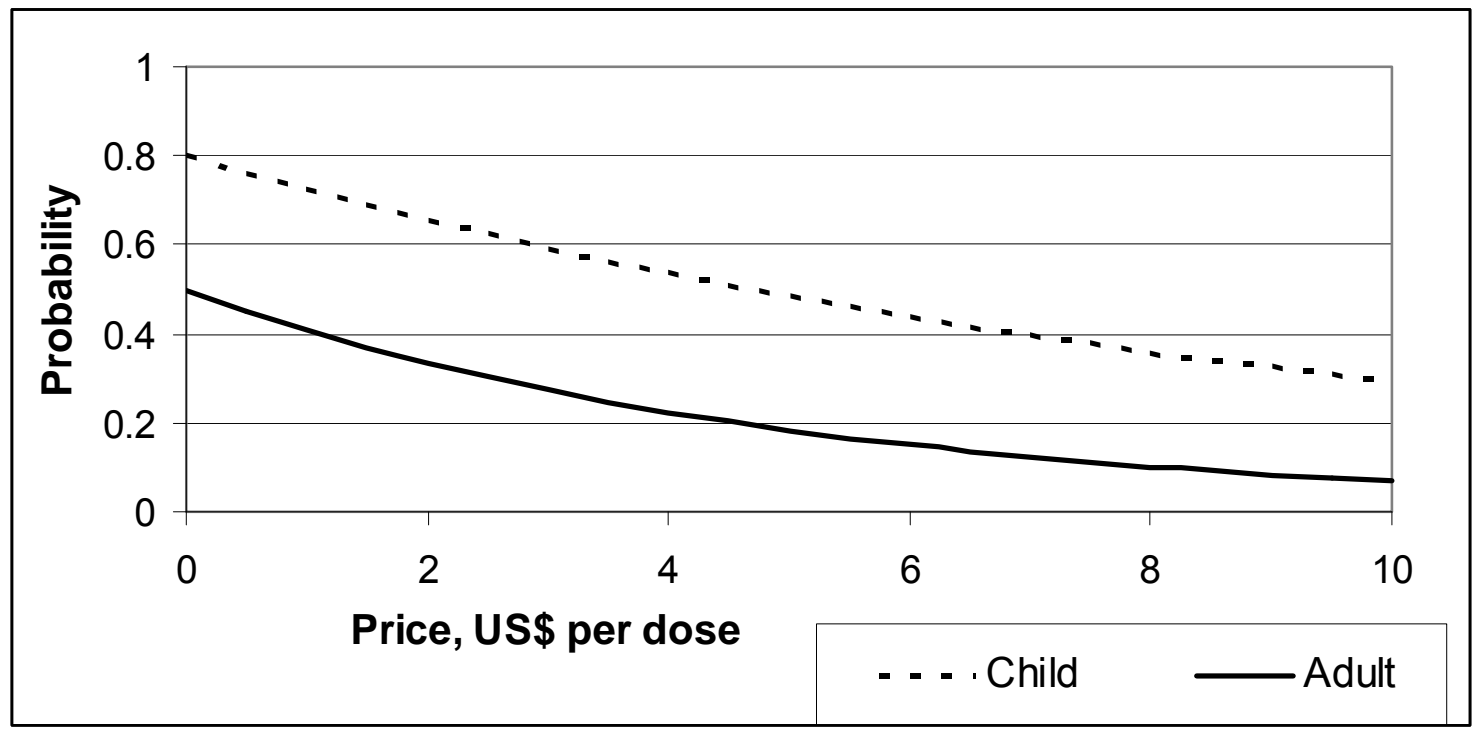

\section{Results}

\section{The optimisation model}

This section presents the results of our application of the optimisation model to the hypothetical target population using the parameter values in Table 1 . We assume that vaccinations are provided in existing health outposts (MCs), where the cost per dose $\left(\mathrm{C}_{c}\right.$ and $C_{a}$ ) is US\$1.0 and the fixed cost is US\$100,000. We assume that neither the government nor external donors are willing to contribute to the program so that $S$ is 0 . In addition, we set $\theta_{c}=\theta_{a}=1$. In other words, we assume that the candidate population is equal to the target population.

We assume further that all new typhoid cases are treated and that government presently spends US $\$ 52,500$ per year treating these patients. ${ }^{2}$ Inserting these parameter values into the model that maximises cases avoided subject to revenue neutrality (equations 4 and 8 ), we obtain the optimal price for children $\left(p_{c}{ }^{*}\right)$ of zero and for adults $\left(p_{a}{ }^{*}\right)$ of US $\$ 2.30$. The optimal results for this example are presented in the third column of Table 2 labeled "Basic Model".

\footnotetext{
${ }^{2}$ Although, we expect that all patients will be treated, the expected typhoid case fatality rate is estimated at about $1 \%$ with treatment. Case fatality rates have been estimated as high as $30 \%$ for severe cases in Indonesia and 4\% for patients at a hospital in Bangladesh (Bhan, Bahl, and Bhatnagar, 2005).
} 
In this Basic Model we see (row 12) that without a vaccination program, there would be a total of about 5,250 cases of typhoid fever over a 3-year period and (row 3 ) that about 2,200 of them (about $40 \%$ ) could be avoided by charging the optimal prices. More than half of the child cases can be avoided $(1,800$ out of 3,150 , rows 7 and 4$)$, which is largely because vaccination is free for children, prompting $80 \%$ of them to be vaccinated. However, only about 470 of the 2,100 adult cases (less than one-quarter) are avoided (rows 11 and 8 ), which is due to the relatively low vaccine demand by adults, (see Figure 1 and row 18, about 220,000 of the 700,000 adults chose vaccination, around $30 \%$ ). Vaccination program costs total about US $\$ 560,000$ (row 36); around US $\$ 57,000(10 \%)$ of the cost would be offset by discounted government treatment savings from avoided typhoid cases (row 31 ), and $90 \%$ of the total cost would be paid by vaccination sales to adults.

From the Basic Model's results, we see that to avoid about 2,200 typhoid cases in the hypothetical target population over a 3-year period, it would be necessary to vaccinate nearly 460,000 persons (row 20), which is more than 200 vaccinations per case avoided. About $90 \%$ of the cost of the vaccination program would have to be covered by revenues from vaccinating adults, who comprise only about half of those vaccinated. Thus, every vaccinated adult would pay not only for her own vaccination but for a child as well. Adults are at lower risk of contracting typhoid fever than children (1 new case per 1,000 adults per year versus 3.5 new cases per 1,000 children per year), and the demand for vaccinations by adults is lower than the demand by children, as shown in Figure 1.

Table 2. Results of Models for Three Unique Typhoid Vaccination Programs over 3

Years

\begin{tabular}{|c|c|c|c|c|}
\hline & & $\begin{array}{l}\text { Basic } \\
\text { Model }\end{array}$ & $\begin{array}{l}\text { Equal-Price } \\
\text { Constraint }\end{array}$ & $\begin{array}{l}\text { Free } \\
\text { Vaccines }\end{array}$ \\
\hline 1 & Optimal child price, $\mathrm{p}_{\mathrm{c}}{ }^{*}$ (US\$) & 0.00 & 1.09 & 0.00 \\
\hline 2 & Optimal adult price, $\mathrm{p}_{\mathrm{a}}{ }^{*}$ (US\$) & 2.27 & 1.09 & 0.00 \\
\hline 3 & Total cases avoided & 2,231 & 2,173 & 2,499 \\
\hline 4 & Child cases without program ( 3 years) & 3,150 & 3,150 & 3,150 \\
\hline 5 & Child cases -not vaccinated & 630 & 890 & 630 \\
\hline 6 & Child cases because ineffective vaccine & 756 & 678 & 756 \\
\hline 7 & Total child cases avoided & 1,764 & 1,582 & 1,764 \\
\hline 8 & Adult cases without program & 2,100 & 2,100 & 2,100 \\
\hline 9 & Adult cases -not vaccinated & 1,433 & 1,255 & 1,050 \\
\hline 10 & Adult cases because ineffective vaccine & 200 & 253 & 315 \\
\hline 11 & Total adult cases avoided & 467 & 591 & 735 \\
\hline 12 & Cases without program & 5,250 & 5,250 & 5,250 \\
\hline 13 & Cases -not vaccinated & 2,063 & 2,145 & 1,680 \\
\hline $\begin{array}{l}14 \\
15\end{array}$ & Cases because ineffective vaccine & 956 & 931 & 1,071 \\
\hline $\begin{array}{l}16 \\
17\end{array}$ & COI avoided (US\$) & 66,921 & 65,199 & 74,970 \\
\hline 18 & Total adults vaccinated & 222,238 & 281,532 & 350,000 \\
\hline 19 & Total children vaccinated & 240,000 & 215,249 & 240,000 \\
\hline $\begin{array}{l}20 \\
21\end{array}$ & Total persons vaccinated & 462,238 & 496,782 & 590,000 \\
\hline 22 & Adults not vaccinated & 477,762 & 418,468 & 350,000 \\
\hline 23 & Children not vaccinated & 60,000 & 84,751 & 60,000 \\
\hline
\end{tabular}




\begin{tabular}{lllll}
\hline 24 & Total persons not vaccinated & 537,762 & 503,218 & 410,000 \\
25 & & & & \\
26 & Revenue from child vaccination sales (US\$) & 0 & 234,283 & 0 \\
27 & Revenue from adult vaccination sales (US\$) & 504,686 & 306,427 & 0 \\
28 & Revenue from total vaccination sales (US\$) & 504,686 & 540,710 & 0 \\
29 & Revenue from child COI avoided (US\$) & 45,511 & 40,818 & 45,511 \\
30 & Revenue from adult COI avoided (US\$) & 12,041 & 15,253 & 18,963 \\
31 & Revenue from total COI avoided (US\$) & 57,552 & 56,071 & 64,474 \\
32 & Revenue from total sales and COI avoided (US\$) & 562,238 & 596,782 & 64,474 \\
33 & & & \\
34 & Variable Cost of Child Vaccinations (US\$) & 240,000 & 215,249 & 240,000 \\
35 & Variable Cost of Adult Vaccinations (US\$) & 222,238 & 281,532 & 350,000 \\
36 & Total Variable Cost of Vaccinations + Fixed Cost (US\$) & 562,238 & 596,782 & 690,000 \\
\hline
\end{tabular}

How can it be 'optimal' to impose most of the financial burden on vaccinating adults, who have only modest risk and many of whom are not inclined to be vaccinated even if the vaccines are provided free of charge? We address this question by examining the optimality condition in equation 10 , which provides insight into the relative magnitudes of optimal child and adult prices. Equation 10 does not contain $\mathrm{N}_{c}$ or $\mathrm{N}_{\mathrm{a}}$, which means that candidate population sizes do not affect the relative prices that should be charged to children and adults, although they do affect the absolute prices through equation 8 . The same is true of $\alpha_{c}$ and $\alpha_{a}$. Another way to say this is that if the conditions in equation 10 are met but those in equation 8 are not (or vice versa), the prices will either be suboptimal (i.e. a different set of prices would increase the number of avoided cases) or infeasible (i.e. the financial cost of the program would exceed the financial returns). If equations 8 and 10 are both satisfied, as in the solution for the Basic Model, the prices are globally optimal.

Equation 10 indicates that it is optimal to make the adult and child vaccine fees equal only if all of the following conditions apply: (1) the costs of treating sick children $\left(\mathrm{COI}_{\mathrm{c}}\right)$ and adults $\left(\mathrm{COI}_{\mathrm{a}}\right)$ are the same, $(2)$ the costs of vaccinating children $\left(\mathrm{C}_{\mathrm{c}}\right)$ and adults $\left(\mathrm{C}_{\mathrm{a}}\right)$ are the same, $(3)$ the incidences of typhoid for children $\left(I_{c}\right)$ and adults $\left(I_{a}\right)$ are the same, and $(4)$ the slopes of the WTP functions for adults $\left(\beta_{\mathrm{a}}\right)$ and children $\left(\beta_{\mathrm{c}}\right)$ are the same. While some of these conditions apply in the assumed target area, not all of them do, which means that the optimal vaccine fees for adults and children should be different if the number of typhoid cases avoided is to be maximised and financial neutrality is to be attained.

Table 1 shows that in the target area, we assume that the marginal costs of vaccinating a child $\left(\mathrm{C}_{\mathrm{c}}\right)$ and an adult $\left(\mathrm{C}_{\mathrm{a}}\right)$ are the same, and the cost of treating a sick child $\left(\mathrm{COI}_{\mathrm{c}}\right)$ is the same as the cost for an adult $\left(\mathrm{COl}_{\mathrm{a}}\right)$. Vaccine efficacy (Eff) is assumed to be the same for adults and children, but there the similarities end. Typhoid incidence in children $\left(I_{c}\right)$ is typically higher than in adults $\left(I_{a}\right)$, and the available evidence suggests that willingness to pay (WTP) for children's vaccinations is higher than for adults.

Because the unit cost of vaccinating children and adults is assumed to be the same, $\mathrm{C}_{c}$ and $\mathrm{C}_{a}$ in equation 10 can be replaced by $\mathrm{C}$, and because the costs of treating sick children and adults are assumed to be the same, $\mathrm{COI}_{\mathrm{c}}$ and $\mathrm{COI}_{\mathrm{a}}$ can be replaced by $\mathrm{COI}$. With these changes, let us set the fee for vaccinating children in equation 10 to zero $\left(p_{c}=0\right)$ and solve the equation for the price charged to adults $\left(p_{a}\right) \ldots$

$$
p_{a}=\left[1 / \beta_{a}+C\right]-\left[1 / \beta_{c}+C\right] . I_{a} / I_{c}
$$


But the fee charged to adults must be greater than zero because if $p_{c}=0$, child vaccinations produce no revenue and the model requires financial self-sufficiency. Hence the right side of equation 12 must exceed zero, yielding ...

$$
\mathrm{I}_{\mathrm{c}} / \mathrm{I}_{\mathrm{a}}>\left(1 / \beta_{\mathrm{c}}+\mathrm{C}\right) /\left(1 / \beta_{\mathrm{a}}+\mathrm{C}\right) \text {. }
$$

Equation 13 is an important result. It says that if this condition holds, the fee charged to children should be zero, and the burden of financing the vaccination program should largely fall upon adults who choose to be vaccinated. ${ }^{3}$ For the assumed parameter values for our target population $\left(\beta_{\mathrm{a}}=0.2, \beta_{\mathrm{c}}=0.1, \mathrm{C}=1\right)$, the numerator of the term on the right side of the equation is 11 and the denominator is 6 . Thus, the optimal price for children is zero if the left side of equation 13 , the ratio of child to adult typhoid incidence, is greater than about $1.8(=11 / 6)$. It follows that under an optimal pricing policy, vaccines in the target area should be free for children largely because child incidence is so much higher than adult incidence. For the conditions in the target area, the only way the child price would not be zero is if the demand for vaccinating children were highly inelastic (or the demand for adults were highly elastic), that is, if the number of children for whom respondents were willing to pay for vaccinations decreased very little as the price they were charged increased. This assumes that revenues from vaccination sales to adults are sufficient to cover free vaccines for children. If the revenues generated at the adult maximum revenue-generating price do not exceed the cost of providing free vaccines for children, this pricing scheme would not be financially feasible.

\section{A Uniform Pricing Policy}

Within this modeling framework, the higher child incidence (relative to adults) of typhoid in the target area means it is optimal to provide vaccinations to children free of charge. This result of the model does not address the logistical or implementation difficulties associated with differential prices for adults and children. Moreover, the practical difficulties associated with such a differential pricing policy are likely to grow when one considers the introduction of multiple vaccines into a population. Also, it may seem unfair to families without children to charge adults higher prices when the cost of vaccinating adults and children is the same.

To address these concerns, we added a constraint to the model, limiting the difference between what adults and children have to pay. The limit selected for this example is zero, such that adults and children must pay the same price. (Obviously, any value could be chosen, as well as a range of values to determine their effects on optimal prices.) The results are shown in the column of Table 2 labeled Equal Price Constraint. Rows 1 and 2 of that column show that the best equalised price for children and adults is about US $\$ 1.10$, which is slightly more than the average variable cost of a vaccination $(C=$ 1.0). This departure from the optimal differential pricing for children and adults has only a small effect on the number of typhoid cases avoided: 60 fewer out of 2,200 (row 3). But reducing the adult price from US $\$ 2.3$ to US\$1.1 would result (row 18) in about $60,000(27 \%)$ more adult vaccinations. The decrease in child vaccinations due to increasing the price from zero to US $\$ 1.1$ is (row 19) about $25,000(10 \%)$. The discounted cost of illness avoided (row 16 ) is only $3 \%$ less than the optimal result from

\footnotetext{
${ }^{3}$ Recall that $1 / \beta$ is the vaccination price that maximizes revenue. Hence, the numerator on the right side of equation 13 is the sum of the revenue-maximizing price and the average cost of a vaccination for children; the denominator is similar except for adults.
} 
the previous Basic Model, and the total program cost (row 36) is US $\$ 35,000$ (6\%) more. Whereas about US\$560,000 in revenue from vaccination sales was needed for our optimal result with the Basic Model, the required revenue from sales due to the equity constraint on child and adult prices is about US $\$ 35,000$ more (row 28) because the increase in adult vaccinations exceeds the decrease in child vaccinations (rows 18 and 19 ) and because fewer cases are avoided (i.e. the reduction in public COI is smaller).

Based on the characteristics of this hypothetical community, it seems that eliminating differential pricing (charging only adults) is no impediment to building a successful vaccination program. It is important to remember that children do not pay for their vaccinations themselves, their parents or adult caregivers do. Compared to the differential pricing scheme, a policy of charging equal vaccine prices for children and adults will result on average in households with a higher ratio of children to adults paying more in total for vaccinations, and households with a lower ratio paying less.

\section{A Policy of Providing Free Vaccines}

Our third model addresses the possibility of supplying vaccines free of charge to both adults and children (see Table 2, column labeled "Free Vaccines"). Recall that the objective is to maximise the number of typhoid cases avoided, which here is shown to be about 2,500 if vaccines were free (row 3). Compared to our original optimal solution, where the adult price is US\$2.30, about $270(12 \%)$ more cases would be avoided in 3 years by making vaccines free. From row 20, 590,000 persons would choose to be vaccinated if vaccines were free, compared to about 460,000 in the optimal solution for the Basic Model, about 130,000 additional vaccinations to avoid an additional 270 cases of typhoid. The financial consequences of offering free vaccines are shown in rows 32 and 36 . No revenue would be generated from sales, so the only receipts would be discounted savings from cases avoided, about US\$64,000. The program cost of US $\$ 690,000$ would produce a financial deficit of about US $\$ 625,000$. Thus, in order to finance a free vaccination program, an external contribution ( $S=U S \$ 625,000$ ) would be required. Based on our demand estimates, this is the maximum possible external contribution. Full subsidisation seems unnecessary based on this example, because free vaccination requires large external contributions and results in only modest increases in cases avoided relative to financially self sufficient programs.

\section{Discussion}

The three models presented above address one of the most important typhoid vaccination policy questions for many developing countries: if users are asked to pay for vaccines, what should the vaccine prices be? As shown, our optimisation model for an assumed target population with characteristics common in South and Southeast Asia provides a basis for selecting them. If differential pricing for adults and children is politically acceptable, then the price for children should be zero and the price for adults should be between US\$1-2.30. (This result ignores the administrative difficulties and transaction costs of actually implementing a differential pricing policy.) Ignoring the uncertainty in the vaccine demand estimates, the analysis also shows that charging adults and children the same price would yield nearly the same financial results and health outcomes. One important conclusion of our analysis is that providing free vaccination might not result in a significant reduction in the number of cases of typhoid compared to either a differential pricing policy or a uniform pricing policy, but it does create a large financial deficit for the government or donor. 
Our models show that the public cost of typhoid treatment avoided by instituting a vaccination program contributes only a very small amount toward financial neutrality. If this contribution were ignored and if the entire cost were instead recovered from vaccination revenues, neither the optimal prices nor the number of cases avoided would be much affected (the optimal price for adults would increase to US\$2.65 and the number of cases avoided would be 2,197.)

Our recommendation to provide free vaccines for children (i.e. the group with highest incidence) is consistent with Patel et al.(2005)'s proposal to prioritise flu vaccines for children. However, we use a pricing mechanism rather than a rationing scheme to ensure that children are vaccinated. The difference is that Patel et al. assume that the number of vaccines is limited, while we assume that financial resources are constrained. This model does not consider the potential for typhoid vaccine herd protection externalities, because there is no epidemiological evidence available. We recommend revisiting the model if vaccine externalities are verified and quantified in the future. Until then, this model should provide an important first step for considering differential pricing and cross-subsidies for vaccines. 


\section{References}

Acosta C., Galindo C., Deen J., Ochiai R., Lee H., Seidlein L.v., Carbis R., Clemens J. (2004). Vaccines against cholera, typhoid fever, and shigellosis for developing countries, Expert Opinion on Biological Therapy 12, 1939-1951.

Barish, N., Kaplan, S. (1978). Economic Analysis for Engineering and Managerial Decision Making. New York, NY: McGraw-Hill.

Bahl R., Sinha A., Poulos C., Whittington D., Sazawal S., Kumar R., Mahalanabis D., Acosta C.J., Clemens J.D., Bhan M.K. (2004). Costs of Illness Due to Typhoid Fever in Indian Urban Slum Community: Implications for Vaccination Policy, Journal of Health, Population and Nutrition 22, 304-310.

Becker N.G., Starczak D.R. (1997). Optimal vaccination strategies for a community of households, Mathematical Biosciences 139, 117-132.

Beutels P., Thiry N., Van Dammea P. (2007). Convincing or Confusing? Economic Evaluations of Childhood Pneumococcal Conjugate Vaccination: A Review (2002-2006), Vaccine 25, 1355-1367.

Bhan M.K., Bahl R., Bhatnagar S. (2005). Typhoid and Paratyphoid Fever, Lancet 366, 749-762.

Boulier B.L., Datta T.S., Goldfarb R.S. 2007. Vaccination Externalities: The B.E, Journal of Economic Analysis \& Policy 7 (1), Article 23.

Brito D.L., Sheshinski E., Intriligator M.D. (1991). Externalities of Compulsory Vaccinations, Journal of Public Economics 45, 69-90.

Canh D., Whittington D., Thoa L., Utomo N., Hoa N.,. Poulos C., Thuy D., Kim D., Nyamete A., Acosta C.J. (2006). Household Demand for Typhoid Fever Vaccines in Hue, Vietnam: Implications for Immunisation Programs, Health Policy and Planning 21 (3), 241-255.

Cavailler P., Lucas M., Perroud V., McChesney M., Ampuero S., Guerin P.J., Legros D., Nierle T., Mahoudeau C., Lab B., Kahozi P., Deen J.L., Seidlein L.V., Wang X.-Y., Puri M., Ali M., Clemens J.D., Songane F., Baptista A., Ismael F., Barreto A., Chaignat C.-L. (2006). Feasibility of a mass vaccination campaign using a twodose oral cholera vaccine in an urban cholera-endemic setting in Mozambique, Vaccine 24, 4890-4895.

Cook J., Johnson F.R., Nyamete A., Canh D.G., Whittington D. (2006). Reliability of Stated Preferences for Vaccines with Time to Think, Economic Inquiry 45 (1), 100-114.

Cropper M.L., Haile M., Lampietti J., Poulos C., Whittington D. (2004). The demand for a malaria vaccine: evidence from Ethiopia, Journal of Development Economics 75, 303-318.

DeRoeck D., Clemens J.D., Nyamete A., Mahoney R.T. (2005). Policymakers' views regarding the introduction of new-generation vaccines against typhoid fever, shigellosis and cholera in Asia, Vaccine 23, 2762-2774.

Francis P.J. (1997). Dynamic Epidemiology and the Market for Vaccinations, Journal of Public Economics 63, 383-406. 
Francis P.J. (2004). Optimal Tax/Subsidy Combinations for the Flu Season, Journal of Economic Dynamics \& Control 28, 2037-2054.

Haber M. (1998). Estimation of the Direct and Indirect Effects of Vaccination, Statistics in Medicine 18, 2101-2109.

Hsu H.C., Lin R.S., Tung T.H., Chen T.H.H. (2003). Cost-benefit analysis of routine childhood vaccination against chickenpox in Taiwan: Decision from different perspectives, Vaccine 21, 3982-3987.

Jacobson S., Sewell E., Deuson R., Weniger B. (1999). An integer programming model for vaccine procurement and delivery for childhood immunisation : a pilot study, Health Care Management Science 2, 1-9.

Kremer M., Glennerster R. (2004). Strong Medicine: Creating Incentives for Pharmaceutical Research on Neglected Diseases. Princeton, NJ and Oxford, UK: Princeton University Press.

Lee G.M.., Murphy T.V., Lett S., Cortese M.M., Kretsinger K., Schauer S., and Lieu T.A. (2007). Cost Effectiveness of Pertussis Vaccination in Adults, American Journal of Preventive Medicine 32 (3), 186-193.

Longini Jr. I.M., Ackerman E., Elveback L.R. (1978). An optimisation model for influenza A epidemics, Mathematical Biosciences 38, 141-157.

Lucas M.E.S., Jeuland M., Deen J., Lazaro N., MacMahon M., Nyamete A., Barreto A., Seidlein L., Cumbane A., Songane F.F.,Whittington D. (2007). Private Demand for Cholera Vaccines in Beira, Mozambique, Vaccine 25, 2599-2609.

Ochiai R.L., Acosta C.J., Danovaro-Holliday M.C., Dong B., Bhattacharya S.K., Agtini M., Bhutta Z.A., Do C.G., Ali M., Shin S., Wain J., Page A.-L., Albert M.J., Deen J.L., Farrar J., Dang D.A., Yang H., Abu-Elyazeed R., Pang T., Xu Z.-y., Galindo C.M., von Seidlein L., Clemens J.D. (2006). A multicenter, population-based, prospective surveillance study of typhoid fever in 5 Asian countries: disease burden and implications for control. Unpublished draft.

Ochiai R.L., Wang X., von Seidlein L., Yang J., Bhutta Z.A., Bhattacharya S.K., Agtini M., Deen J.L., Wain J., Kim D.R., Ali M., Acosta C.J., Jodar L., Clemens J.D. (2005). Salmonella Paratyphi A Rates, Asia, Emerging Infectious Diseases 11, 1764-1766.

Patel R., Longini Jr. I.M., Halloran M.E. 2005. Finding optimal vaccination strategies for pandemic influenza using genetic algorithms, Journal of Theoretical Biology 234, 201-212.

Poulos C., Nyamete A., Stewart J., Deen J., Seidlein L., Whittington D., et al. (2007). Cost of illness due to typhoid fever in five Asian countries. Report to the International Vaccine Institute, Seoul, Korea.

Stewart J.F. (2005). Vaccination cost: Vi polysaccharide typhoid vaccine In Vietnam, India, and Indonesia. Report to the International Vaccine Institute, Seoul, Korea.

Suraratdecha C., Ainsworth M., Tangcharoensathien V., Whittington D. (2005). Private demand for an AIDS vaccine in Thailand, Health Policy 71, 271-287.

Szucs T.D. 2005. Health Economic Research on Vaccinations and Immunisation Practices-an Introductory Primer, Vaccine 23, 2095-2103. 
Thiem V.D., Hossain M.M., Son N.D., Hoa N.T., Rao M.R., Canh D.G., Naficy A., Ke N.T., Acosta C.J., Deen J.L., Clemens J.D., Trach D.D. (2003). Coverage and costs of mass immunisation of an oral cholera vaccine in Vietnam, Journal of Health, Population and Nutrition 21, 304-308.

Weniger B.G., Chen R.T., Jacobson S.H., Sewell E.C., Demon S.R., Livengood J.R., Orenstein W.A. (1998). Addressing the challenges to immunisation practice with an economic algorithm for vaccine selection, Vaccine 16, 1885-I 897.

Whittington D., Matsui-Santana O., Freiberger J.J., Houtven G.V., Pattanayak S. (2002). Private demand for a HIVIAIDS vaccine: Evidence from Guadalajara, Mexico, Vaccine 20, 2585-2591.

Whittington D., Pinheiro A.C., Cropper M.L. (2003). The economic benefits of malaria prevention: A contingent valuation study in Marracuene, Mozambique, Journal of Health and Population in Developing Countries, www.jhpdc.unc.edu/2003 papers/ ecowhit.pdf

Yang H.H., Kilgore P.E., Yang L.H., Park J.K., Pan Y.F., Kim Y., Lee J.K., Xu Z.Y., Clemens J.D. (1999). An outbreak of typhoid fever, Xing-An County, People's Republic of China, 1999: Estimation of the field effectiveness of $\mathrm{Vi}$ polysaccharide typhoid vaccine, Journal of Infectious Diseases 183, 1775-1780. 


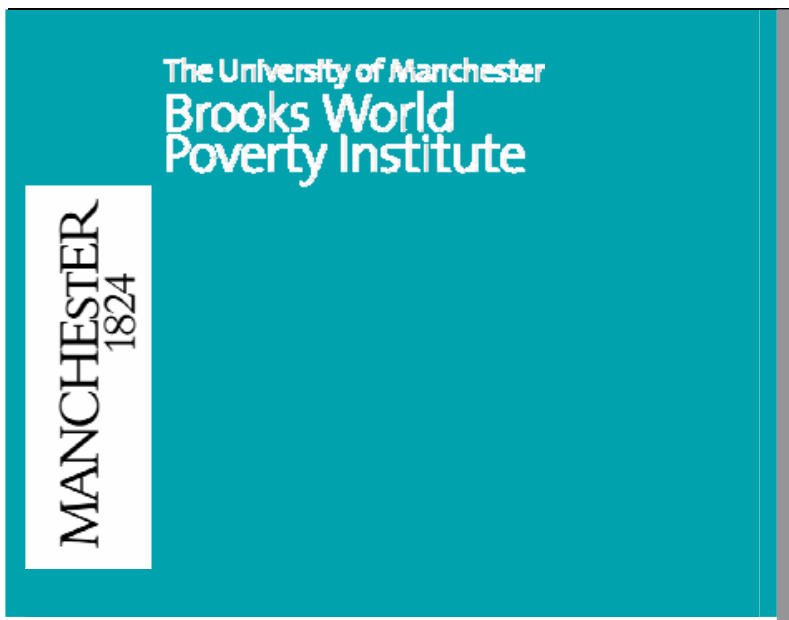

Executive Director

Professor Tony Addison

\section{Research Director}

Professor Michael Woolcock

\section{Associate Director}

Professor David Hulme

\section{Contact:}

Brooks World Poverty Institute

The University of Manchester

Humanities Bridgeford Street

Building

Oxford Road

Manchester

M13 9PL

United Kingdom

Email: bwpi@manchester.ac.uk
The Brooks World Poverty Institute (BWPI) creates and shares knowledge to help end global poverty.

BWPI is multidisciplinary, researching poverty in both the rich and poor worlds.

Our aim is to better understand why people are poor, what keeps them trapped in poverty and how they can be helped - drawing upon the very best international practice in research and policy making.

The Brooks World Poverty Institute is chaired by Nobel Laureate, Professor Joseph E. Stiglitz. 